\title{
EDITORIAL
}

\section{The importance of long-term follow-up in pediatric hematopoietic stem cell transplantation}

Bone Marrow Transplantation (2015) 50, 749-750; doi:10.1038/ bmt.2015.70; published online 13 April 2015

Allogeneic hematopoieitic stem cell transplantation (HSCT) is a curative therapy for many high-risk leukemias and non-malignant conditions, such as immunodeficiencies, beta-thalassemia, sickle cell anemia and metabolic disorders. Most outcome studies of transplant focus on early outcomes, in the first few years after transplant, namely relapse incidence and non-relapse mortality. A major question that remains is what is the outcome patients 10 or 20 years after their transplant? The few pediatric late effects studies have shorter follow-up or don't follow their patients past puberty or adulthood. ${ }^{1-3}$

The beauty of the Wilhelmsson study is that it includes data from every single long-term survivor (survived $>4$ years) from the pediatric HSCT programs at Karolinska, Sweden and Helsinki, Finland. They maintained careful records, from at least yearly visits on late effects, including (among others) hormonal and nonhormonal adverse events and growth impairments. A total of 204 patients were followed in this study. The authors must be congratulated for collecting this longitudinal information, which could have the tendency in a busy transplant program, focusing on the active patients frequently in treatment.

A most important finding is that the incidence and severity of chronic health conditions is high, with $41 \%$ of patients having had at least one grade 3 condition. There were more in the Busulfan or TBI recipients. There were also more chronic health conditions in patients that had had chronic GvHD. Also worthy of mention is that growth impairment is a major long-term issue, with patients transplanted pre-puberty and/or those with TBI had the greatest loss to potential adult height reached.

A major strength of this publication is certainly that these sites were truly dedicated to collecting this information, making it more likely that these late effects were captured. In larger studies that involve multiple sites submitting data, the quality of data may not necessarily be as robust. Not all centers may have the same ability to submit data, and if a center is not truly focused on eliciting late effects and chronic health conditions from their patients, they may just not have this information. On the other hand, the fact that it is based on only two sites raises concerns that data from this homogeneous sample may not be as representative of the whole pediatric transplant population. These patients may potentially be at higher or lower risk for certain chronic health conditions.

What should pediatric transplanters do with this information? From a clinical standpoint, it helps a great deal when trying to educate families on what the future may look like, 10 or 20 years down the road. Often when moving quickly to transplant families may have a hard time hearing what the long-term future may look like, as they are so concentrated on the cure. However, touching upon these late effects is our duty, and especially once patients are surviving 1 or 2 years after transplant and are seen infrequently, this is an excellent time to frankly discuss potential late effects and give anticipatory guidance. Many programs have dedicated long-term follow-up clinics, which are the optimal place for the detection of these conditions and transmission of information. Second, this information may truly be very important for patients and families that do have an option, and are trying to decide between transplant and no transplant. Some instances that come to mind are a late relapse ALL patient with a match-sib, who may have very similar survival outcomes if treated with transplant or additional chemotherapy. Taking late effects of each treatment into consideration may help with that decision. Another instance, which we are more and more frequently facing in pediatric HSCT, is sickle cell anemia. ${ }^{4}$ Without impending mortality, many of these patients often have the luxury of time to make the decision of transplant, and this decision should take into account the potential late effects of transplant as compared with the cumulative effects on health and quality of sickle cell anemia, non-transplanted.

From an academic standpoint, it should be a call to action. With such a high incidence of late effects due to our intensive therapies, we should work hard to find alternative strategies to avoid high doses of chemotherapy and/or radiation. There is a lot of excitement around T-cell therapy for leukemia, such as chimeric antigen receptor T cells, ${ }^{5}$ and it would be tremendous progress to be able to use this therapy instead of a transplant, or at least coupled with a very reduced intensity transplant, instead of a myeloablative transplant. Second, chronic GvHD remains a main factor contributing to chronic health conditions, likely because of all the toxic therapies needed to treat chronic GvHD. Therefore, continuing to find novel ways to avoid chronic GvHD (especially by avoiding acute GvHD) are of paramount importance. For example, a current study within the Pediatric Blood and Marrow Transplant Consortium is examining whether abatacept added to post-transplant GvHD prophylaxis in leukemia recipients of unrelated donor leads to lower GvHD burden. ${ }^{6}$ Continuing to identify biomarkers so we can hopefully treat or prevent GvHD before it manifests itself ${ }^{7}$ should also continue to be on the agenda.

And from a programmatic standpoint, centers should be encouraged to put an emphasis on their long-term follow-up clinics, both to adequately educate their patients about late effects and to identify these conditions early. The latter may lead to improved outcomes with these conditions. Finally adequate documentation of late effects, and robust data capture at the center level is essential, to contribute complete information to organizations such as CIBMTR. All of these efforts will help us continue to move the needle and improve transplant outcomes of our pediatric patients.

\section{CONFLICT OF INTEREST}

The authors declare no conflict of interest.

DA Jacobsohn

Department for Pediatric Bone Marrow Transplantation, Children's National Health System, Washington, DC, USA E-mail: dajacobs@childrensnational.org

\section{REFERENCES}

1 Ferry C, Gemayel G, Rocha V, Labopin M, Esperou H, Robin M et al. Long term outcomes after allogeneic stem cell transplantation for children with hematological malignancies. Bone Marrow Transplant 2007; 40: 219-224.

2 Kunkele A, Engelhard M, Hauffa BP, Mellies U, Muntjes C, Huer C et al. Long-term follow-up of 368 pediatric patients receiving total body irradiation before 
hematopoietic stem cell transplantation and post-transplant survival of $>2$ years. Pediatr Blood Cancer 2013; 60: 1792-1797.

3 Faraci M, Bekassy AN, De Fazio V, Tichelli A, Dini G. Non-endocrine late complications in children after allogeneic haematopoietic SCT. Bone Marrow Transplant 2008; 41: S49-57.

4 Thompson AL, Bridley A, Twohy E, Dioguardi J, Sande J, Hsu LL et al. An educational symposium for patients with sickle cell disease and their families: results from surveys of knowledge and factors influencing decisions about hematopoietic stem cell transplant. Pediatr Blood Cancer 2013; 60: 1946-51.
5 Maude SL, Shpall EJ, Grupp SA. Chimeric antigen receptor T-cell therapy for ALL. Hematology Am Soc Hematol Educ Program 2014; 2014: 559-564.

6 Koura DT, Horan JT, Langston AA, Qayed M, Mehta A, Khoury HJ et al. In vivo T cell costimulation blockade with abatacept for acute graft-versus-host disease prevention: a first-in-disease trial. Biol Blood Marrow Transplant 2013; 19: 1638-1649.

7 Vander Lugt MT, Braun TM, Hanash S, Ritz J, Ho VT, Antin JH et al. ST2 as a marker for risk of therapy-resistant graft-versus-host disease and death. N Engl J Med 2013; 369: 529-39. 